Article

\title{
Assessing the Accuracy of Forest Phenological Extraction from Sentinel-1 C-Band Backscatter Measurements in Deciduous and Coniferous Forests
}

\author{
Yuxiang Ling ${ }^{1,2}$, Shiwen Teng ${ }^{1,2, *(\mathbb{D})}$, Chao Liu ${ }^{1,2}$, Jadunandan Dash ${ }^{3}$, Harry Morris ${ }^{3}$ and Julio Pastor-Guzman ${ }^{3,4}$ \\ 1 Collaborative Innovation Center on Forecast and Evaluation of Meteorological Disasters, Nanjing University \\ of Information Science \& Technology, Nanjing 210044, China; yl10m19@southamptonalumni.ac.uk (Y.L.); \\ chao_liu@nuist.edu.cn (C.L.) \\ 2 Key Laboratory for Aerosol-Cloud-Precipitation of China Meteorological Administration, School of \\ Atmospheric Physics, Nanjing University of Information Science \& Technology, Nanjing 210044, China \\ 3 School of Geography and Environmental Science, University of Southampton, Highfield, \\ Southampton SO17 1BJ, UK; J.DASH@soton.ac.uk (J.D.); h.morris@soton.ac.uk (H.M.); \\ julio.pg@bahia.tecnm.mx (J.P.-G.) \\ 4 Tecnológico Nacional de México/IT Bahía de Banderas, Crucero a Punta de Mita S/N, \\ Bahia de Banderas C.P. 63734, Mexico \\ * Correspondence: tengshiwen@nuist.edu.cn
}

check for updates

Citation: Ling, Y.; Teng, S.; Liu, C.; Dash, J.; Morris, H.; Pastor-Guzman, J. Assessing the Accuracy of Forest Phenological Extraction from Sentinel-1 C-Band Backscatter Measurements in Deciduous and Coniferous Forests. Remote Sens. 2022, 14, 674. https://doi.org/10.3390/ rs14030674

Academic Editors: Nikos Koutsias, Alexandra Gemitzi and Sofia Bajocco

Received: 5 December 2021

Accepted: 27 January 2022

Published: 31 January 2022

Publisher's Note: MDPI stays neutral with regard to jurisdictional claims in published maps and institutional affiliations.

Copyright: (C) 2022 by the authors. Licensee MDPI, Basel, Switzerland. This article is an open access article distributed under the terms and conditions of the Creative Commons Attribution (CC BY) license (https:// creativecommons.org/licenses/by/ $4.0 /)$.

\begin{abstract}
Satellite remote sensing is an important method for forest phenological studies at continental or global scales. Sentinel-1 (S1), a polar orbit satellite with a spatial resolution of $10 \mathrm{~m}$, provides an opportunity to observe high-resolution forest phenology. The sensitivities of S1 C-band backscatter measurements to vegetation phenology, such as crops, meadows, and mixed forests, have been discussed, whereas their performance for different forest types has not yet been quantitatively assessed. It is necessary to evaluate accuracy before adapting S1 datasets in forest phenological studies. This study discusses the seasonal variations in S1 backscatter measurements and assesses the accuracy of S1-based forest phenological metrics in two types of typical forests: deciduous and coniferous. S1 C-band SAR dual-polarization backscatter measurements for the period 2017-2019 were used to extract forest phenology metrics using the Fourier transform (FT) and double logistic (DL) functions. Phenological metrics from the ground-based PhenoCam dataset were used for evaluation. The S1 backscatter VV-VH signal peaks for deciduous and coniferous forests occur in the winter and summer, respectively. The S1 backscatter could reasonably characterize the start of season (SOS) of deciduous forests, with $\mathrm{R}^{2}$ values up to 0.8 , whereas the $\mathrm{R}^{2}$ values for coniferous forest SOS were less than 0.30 . Moreover, the retrieved end of season (EOS) was less accurate than the SOS. The differences in accuracy of S1 backscatter phenological metrics between deciduous and coniferous forests can be explained by the differences in seasonal changes in their corresponding canopy structures. To conclude, S1 C-band backscatter has a reasonable performance when monitoring the SOS of deciduous broadleaf forests $\left(R^{2}=0.8\right)$ and relatively poor performance when extracting EOS of deciduous broadleaf forests $\left(R^{2}=0.25\right)$ or phenology of evergreen needleleaf forests $\left(R^{2}=0.2\right)$.
\end{abstract}

Keywords: sentinel-1; forest phenology; time-series; PhenoCam; NDVI

\section{Introduction}

Forests are important ecosystems that produce natural biological resources for humans [1,2]. As a major terrestrial ecosystem, forests play essential roles in providing habitats for biomes, which maintain the global energy and material cycle, balancing greenhouse gas concentrations in the atmosphere and maintaining climate stability. Forest phenology is a key variable in conducting scientific management of forestry and has become important in climate change studies $[3,4]$. 
Forest phenology refers to the sensitive reactions of forest vegetation biological events to seasonal variations in environmental variables such as temperature and humidity [5]. These reactions make forests the most sensitive indicator of environmental conditions [3,4]. The end of season (EOS) of broadleaf temperate deciduous forests of the eastern USA was widely delayed by 0.8 days per year from 1988 to 2008 [6]; an advanced trend was found at the start of season (SOS) of North American species [7], both clearly indicating the impact of global warming. Thus, accurate and detailed forest phenological measurements are essential not only for forestry management but also for climate change studies. Therefore, it is necessary to efficiently and economically monitor forest phenology.

Observations of vegetation phenology have evolved over time. Traditional phenological observations are based on ground surveys and refer to human visual observations of the seasonal and annual variation in the biophysical dynamics of selected species [8]. The history of phenological ground surveys can be traced back to the observation of cherry blossoms in 705 AD in Japan [9], while Europe and the US have formed observation networks to record phenological information [10]. This method can provide accurate phenological information of specific species and is independent of instruments. However, the established observation networks can only cover a small localized area [8]. Furthermore, the standards for phenological records could be different, and records may contain biases due to times for budburst [6] or leaf opening [11] or to the amount of biomass [12]. Therefore, it is difficult to extend such observations to continental or global vegetation phenological studies.

To overcome the limitation of ground surveys, remote sensing technologies have been utilized and both ground-based and satellite remote sensing approaches have been developed. Satellite remote sensing has the advantage of wider observational ranges and can be utilized in a broad range of applications. Common optical satellites such as NOAA, Terra, and Landsat can provide reliable observation data sources for phenological studies, along with some Synthetic Aperture Radar (SAR) measurements such as those obtained by the Sentinel-1 (S1) satellite [13-15]. Ground-based remote sensing can provide accurate site-level data but is restricted by the cost of instruments and frequency of the observations. However, these ground-based data can be used as references to evaluate the accuracy of satellite retrievals [12]. These methods can monitor vegetation over wider areas, longer time periods and can promote the development of phenological research. Therefore, remote sensing products have been widely used in recent studies. In phenological studies, passive optical remote sensing mainly focuses on microstructures of the vegetation such as chlorophyll which absorb red bands and leaf cells reflect near-infrared bands [16], while SAR products focus on the backscatter to determine the structure of leaves and branches [17]. The recently launched Sentinel-1 (S1) and Sentinel-2 (S2) satellites developed by the European Space Agency within the Copernicus Program have a 6-day and a 5-day repeat cycle respectively and have made a significant contribution in providing reliable surface remote sensing data with high spatial and temporal resolutions [15]. SAR measurements are obtained through active remote sensing techniques and thus can provide observations that are not influenced by cloud or sunlight, which can influence the quality of optical datasets.

S1 datasets showed great success in vegetation phenological studies, such as for estimating crop phenology [18,19], classifying mixed temperate forests [2], and determining meadow phenology [20]. Moreover, for forest phenology, some studies have started to use $\mathrm{S} 1$ backscatter measurements to explore forest temporal characteristics, such as the seasonal variations of temperate forest [1], forest biomass estimation [21,22] and forest damage degree [23]. Current studies of optical sensors have not been satisfied with the accuracy of phenological extraction $\left(\mathrm{R}^{2}\right.$ value of approximately 0.5$)$ and are considering introducing S1 to improve the accuracy [20]. Therefore, it is necessary to assess the accuracy of phenological extraction with S1 backscatter measurements.

To conclude, it is still unclear how accurate phenological retrieval based on S1 backscatter would be for forests of different types. Thus, this study investigates the accuracy of retrieving phenology for deciduous and coniferous forest sites across North America using 
S1 backscatter measurements. An evaluation of the S1 derived phenological metrics was performed against an independent in-situ dataset obtained from the PhenoCam network. Additionally, an inter-comparison against S2 NDVI derived phenology was also performed.

\section{Materials and Methods}

\subsection{Study Sites}

The climate of North America east of $110^{\circ} \mathrm{W}$ can be generally divided into tropical monsoon, humid subtropical, and humid continental climates from south to north, while it is mainly a semiarid steppe climate west of $110^{\circ} \mathrm{W}$. Forest types are significantly affected by climate; evergreen coniferous forests are mainly distributed in humid subtropical and semiarid steppe climates, while deciduous broadleaf forests are mainly distributed in humid continental climates.

The National Ecological Observatory Network (NEON) is a nationwide network established to observe the environment at the regional and continental scales [24]. The network composed of 20 regional networks covers most major forests and water bodies to observe biodiversity and ecosystem functions and plays important roles in studying environmental changes and predicting their trends. From the 20 regional networks, 26 field sites with observations between 2017 and 2019 were considered. The stations are evenly distributed in deciduous broadleaf (DB) forests and evergreen needleleaf (EN) forests and cover as wide longitude and latitude spans as possible to observe the influence of climate on forest phenology. The locations and forest types of the selected field sites were given in NEON [25], as shown in Table 1, and marked in Figure 1.

Table 1. Information of selected field sites (14 deciduous broadleaf sites and 12 evergreen needleleaf sites) and the corresponding data availability.

\begin{tabular}{|c|c|c|c|c|c|c|}
\hline \multirow{2}{*}{ Domain Number } & \multirow{2}{*}{ Site Name } & \multirow{2}{*}{ Latitude } & \multirow[t]{2}{*}{ Longitude } & \multirow{2}{*}{$\begin{array}{c}\text { Data } \\
\text { Coverage }\end{array}$} & \multicolumn{2}{|c|}{$\begin{array}{c}\text { Satellite } \\
\text { Cycle (Day) }\end{array}$} \\
\hline & & & & & S1 & S2 \\
\hline \multicolumn{7}{|c|}{ Deciduous Broadleaf (DB) } \\
\hline D01 & BART & 44.06387 & -71.28738 & 2017-2019 & 6 & 5 \\
\hline D01 & HARV & 42.53691 & -72.17265 & 2017-2019 & 12 & 5 \\
\hline D02 & SCBI & 38.89293 & -78.13949 & 2017-2019 & 6 & 5 \\
\hline D02 & SERC & 38.89008 & -76.56001 & 2017-2019 & 6 & 5 \\
\hline D05 & STEI & 45.50894 & -89.58637 & 2018-2019 & 12 & 5 \\
\hline D05 & TREE & 45.49373 & -89.58572 & 2017-2019 & 12 & 5 \\
\hline D05 & UNDE & 46.23391 & -89.53725 & 2017-2019 & 12 & 5 \\
\hline D06 & UKFS & 39.04043 & -95.19215 & 2019 & 6 & 5 \\
\hline D07 & GRSM & 35.68896 & -83.50195 & 2017-2019 & 6 & 5 \\
\hline D07 & MLBS & 37.37831 & -80.52485 & 2017-2019 & 6 & 5 \\
\hline D07 & ORNL & 35.96413 & -84.28259 & 2017-2019 & 6 & 5 \\
\hline D08 & DELA & 32.54173 & -87.80388 & 2017-2019 & 12 & 5 \\
\hline D08 & LENO & 31.85388 & -88.16122 & 2017-2019 & 12 & 5 \\
\hline D11 & CLBJ & 33.40123 & -97.57000 & 2017-2019 & 6 & 5 \\
\hline \multicolumn{7}{|c|}{ Evergreen Needleleaf (EN) } \\
\hline D02 & BLAN & 39.03370 & -78.04179 & 2017-2019 & 6 & 5 \\
\hline D03 & JERC & 31.19484 & -84.46862 & 2017 & 6 & 5 \\
\hline D03 & OSBS & 29.68928 & -81.99343 & 2017-2019 & 12 & 5 \\
\hline D08 & TALL & 32.95047 & -87.39326 & 2017-2019 & 6 & 5 \\
\hline D10 & RMNP & 40.27590 & -105.54596 & 2017-2019 & 6 & 5 \\
\hline D12 & YELL & 44.95348 & -110.53914 & 2019 & 6 & 5 \\
\hline D16 & ABBY & 45.76243 & -122.33033 & 2018 & 12 & 5 \\
\hline D16 & WREF & 45.82049 & -121.95191 & 2019 & 12 & 5 \\
\hline D17 & SJER & 37.10878 & -119.73228 & 2019 & 6 & 5 \\
\hline D17 & SOAP & 37.03337 & -119.26219 & 2018-2019 & 6 & 5 \\
\hline D19 & BONA & 65.15401 & -147.50258 & 2019 & 12 & 5 \\
\hline D19 & DEJU & 63.88112 & -145.75136 & 2017-2019 & 12 & 5 \\
\hline
\end{tabular}




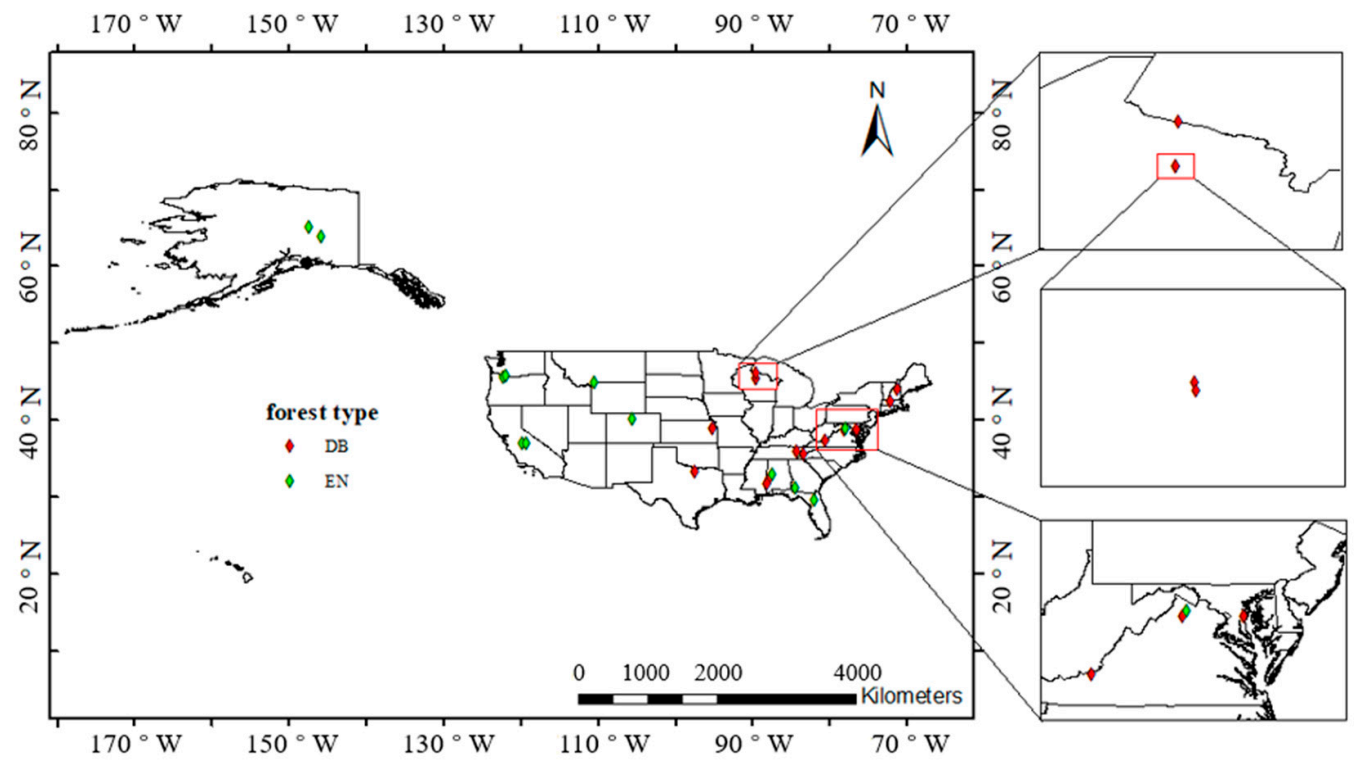

Figure 1. Map of the US and study sites. DB: deciduous broadleaf forest, EN: evergreen needleleaf forest.

\subsection{PhenoCam Data}

The PhenoCam dataset provides digital camera images composed of three channels, red (R), green (G), and blue (B), and can be used to derive vegetation statistics and vegetation index in the region of interest (ROI) based on given masks. The provided dataset consists of time series of digital number (DN) and vegetation indices (VIs) that can reveal phenological changes [26], including the RGB chromatic coordinates (i.e., Rcc, Gcc, and $\mathrm{Bcc})$. The Gcc can be defined as:

$$
\mathrm{Gcc}=\frac{\mathrm{G}}{\mathrm{R}+\mathrm{G}+\mathrm{B}}
$$

where RGB represents the DN of the red, green, and blue channels. Gcc has been more widely used in recent studies and PhenoCam networks because it can decrease the effect of environmental illumination, thus enhancing the monitoring of vegetation dynamics $[12,27-32]$.

The Level 3 product of the PhenoCam dataset includes the statistics of DN and VIs of each image with a time resample of $30 \mathrm{~min}$, taken from cameras at a height of $-300 \mathrm{~m}$, while the Level 4 product includes 1 and 3-day averages for contents of Level 3. The PhenoCam dataset applies spline interpolation to remove Gcc outliers caused by environmental variables when processing Level 4 time series into Level 5 products when extracting the phenological metrics. Dynamic thresholds of the 10th, 25th, and 50th quantiles were applied to determine the SOS and EOS from Level 5 products on the rising or falling amplitudes, respectively [26].

The PhenoCam datasets have been validated to be consistent with ground observations, near-surface radiometry, and satellite remote sensing by Richardson et al. [33] In this study, the transition date in Level 5 product with a threshold of the 50th quantile of the amplitude was used for subsequent statistical analysis as a representation of in-situ measurements.

\subsection{Sentinel-1 and-2 Data}

S1 and S2 are a part of the Copernicus Program satellite constellation (including Sentinel-1, -2, and -3) developed by the European Space Agency (ESA). The C-band SAR onboard S1 provides dual-polarization (i.e., VV and VH) observations and integrates four imaging modes with different resolutions and coverages [34]. This study used the S1A and S1B Level-1 Ground Range Detected (GRD) product from January 2017 to December 2019, 
and the resolution of the product was $10 \mathrm{~m}$. The backscatter coefficient of VV and VH of each study site was replaced by an average with a $15 \times 15$ kernel to reduce the inherent speckle effects of radar imagery. For each site, two polarization combinations discussed in previous studies $[1,21]$, i.e., the ratio VH/VV and the differencing VV-VH, were extracted to analyze the effect of phenological estimation.

In addition, S2 Level-1C data were used to compare the accuracy of S1 retrieval. The Level-1C products consist of 13 spectral bands at spatial resolutions from $10 \mathrm{~m}$ to $60 \mathrm{~m}$, and B4 (centered at $665 \mathrm{~nm}$ ) and B8 (centered at $842 \mathrm{~nm}$ ) used in this study were at a resolution of $10 \mathrm{~m} \mathrm{[35].} \mathrm{A} \mathrm{cloud} \mathrm{mask} \mathrm{band} \mathrm{(QA60)} \mathrm{was} \mathrm{used} \mathrm{to} \mathrm{pick} \mathrm{only} \mathrm{cloud-free} \mathrm{pixels.}$ Scenes where more than $30 \%$ of the pixels within the subset were classified as cloudy were removed from the analysis.

Then, the normalized difference vegetation index (NDVI), which reveals the difference between leaf spectral absorption and reflection, was calculated based on B4 and B8 reflectance using the following equation [36]:

$$
\mathrm{NDVI}=\frac{\mathrm{B} 8-\mathrm{B} 4}{\mathrm{~B} 8+\mathrm{B} 4}
$$

Cloudy pixels (derived from the QA60) and water bodies (pixels with NDVI values less than 0 ) were removed to ensure only pixels of good quality were used for further analysis.

\subsection{Phenological Metrics Extraction}

Satellite remote sensing time series are affected by environmental conditions such as clouds and atmospheric contaminants, and the viewing angle of the satellite instruments can introduce additional uncertainties. To enhance the seasonal variations of interest indices, it is necessary to apply cleaning and curve-fitting methods to enhance the annual variations of the time series.

Before fitting, data cleaning and smoothing were performed to reduce the noise influences. First, the obtained time series were filtered to remove outliers using the method proposed by Timesat 3.3 [37]. When iterating over the time series, the following criteria were used to remove outliers: data points that exceeded 2 standard deviations (named as a cutoff) away from the mean of the time series, less than the average of its nearest validate values in the time series (named as immediate neighbors) minus the cutoff, or higher than the maximum of its immediate neighbors plus the cutoff.

Fourier transform (FT), a basic signal-processing method, is a traditional signal noise reduction technique that conducts frequency domain analysis and has been applied in a number of phenological studies [38,39]. Evenly spaced time series are required in FT; therefore, the pre-processed time series were binned into 10-day windows and the average value was calculated to characterize the signal. Linear interpolation of the immediate neighbor windows was used to fill gaps in the time series. If satellite data was consecutively missing for more than 30 days (which occurred in the S2 data of 2017 and 2018 in this research), the data before the missing period would be discarded to reduce the effect of linear interpolation on the curve-fitting accuracy. The FT decomposes signals into a series of harmonics sorted by frequency and one base value, in which non-periodic noise is usually characterized by high-frequency harmonics and seasonal trends are usually characterized by harmonics of lower frequency [40]. The non-periodic noise can be removed after inverse FT is conducted using the first few low-frequency harmonics and the base value [41]. Pastor-Guzman et al. [42] reported that with the first four harmonics and the base value, the phenological profile can be reconstructed reasonably, and this study conducted the inverse FT in the same way.

The DL function was constructed using two logistic functions to simulate the single peak phenology. Its basis function can be written as [43]:

$$
\mathrm{g}\left(\mathrm{t}, a_{1}, a_{2}, b_{1}, b_{2}, \mathrm{c}, \mathrm{d}\right)=\mathrm{c}+\mathrm{d}\left(\frac{1}{1+e^{b_{1}\left(a_{1}-t\right)}}-\frac{1}{1+e^{b_{2}\left(a_{2}-t\right)}}\right)
$$


where $a_{1}, a_{2}$ are the inflection points of the growing period and falling period, respectively, $b_{1}, b_{2}$ are the slopes of $a_{1}, a_{2}$, respectively, $\mathrm{c}$ is the minimum value of the curve, and $\mathrm{d}$ is the amplitude of the curve. A non-linear least square function was considered in the curve fitting. Each DL function can fit the time series of polarization combinations or NDVI for one growing season, approximately one year for forests, so the time series were divided by year during the DL curve fitting.

The FT, the inverse FT, and the curve fitting process of the DL were performed in Python 3.8. The FT and the inverse FT were conducted by NumPy [44], while the curve fitting was conducted by a least-squared optimization method from SciPy [45].

To facilitate the comparison of phenological phases extracted by this research and the phenological metrics in the PhenoCam Level 5 product, the same dynamic threshold method was applied to extract the phenological metrics, for each growing period or falling period, $50 \%$ of its amplitude was set as the threshold [26]. Figure 2 shows the curve fitting and the extracting of phenological metrics. The first day, when the data increase exceeded the threshold, was marked as SOS, and the first day when the data decreased below the threshold was marked as EOS. Then, the correlation $\mathrm{R}^{2}$ values between the estimated phenological dates from S1 backscatter, S2 NDVI and PhenoCam Gcc were used to evaluate the reliability of the phenological metrics obtained from different techniques. Figure 3 summarizes the forest phenology extracting and evaluation.

(a) Fourier transform

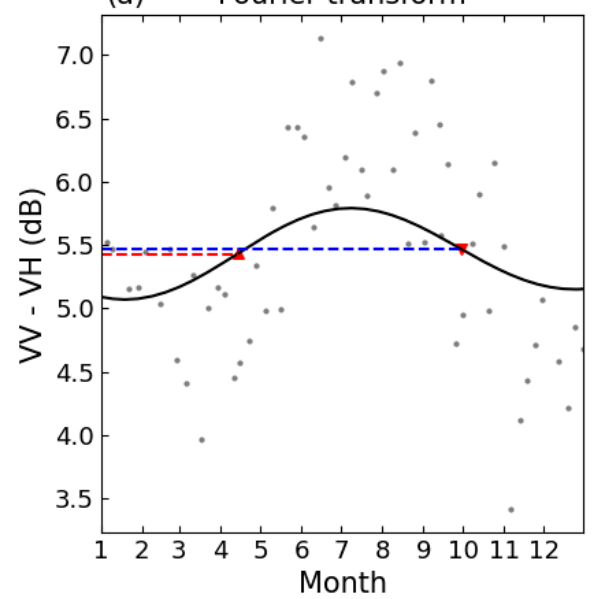

(b)

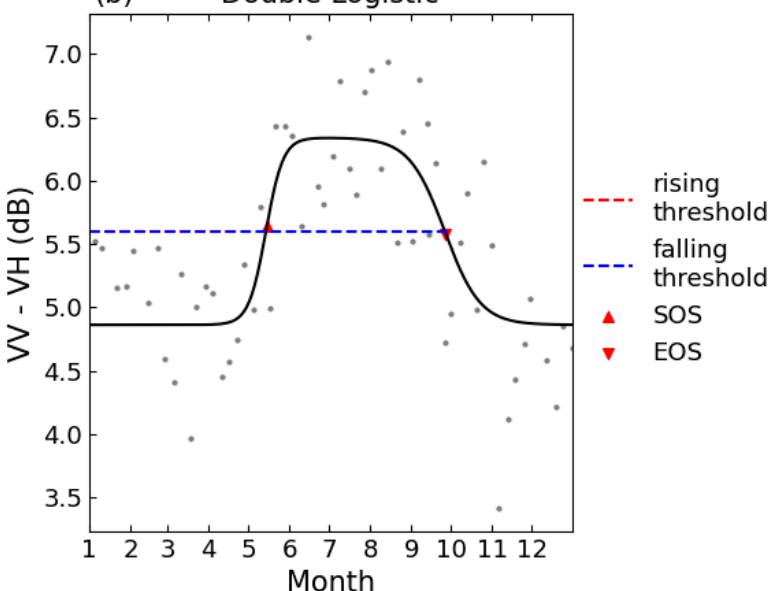

Figure 2. Schematics of curve fitting for (a). FT and (b). DL. Threshold for the phenological metrics was set as $50 \%$ of either the rising or falling period. The time series shown is for the 2018 growing season at site D02.SCBI.

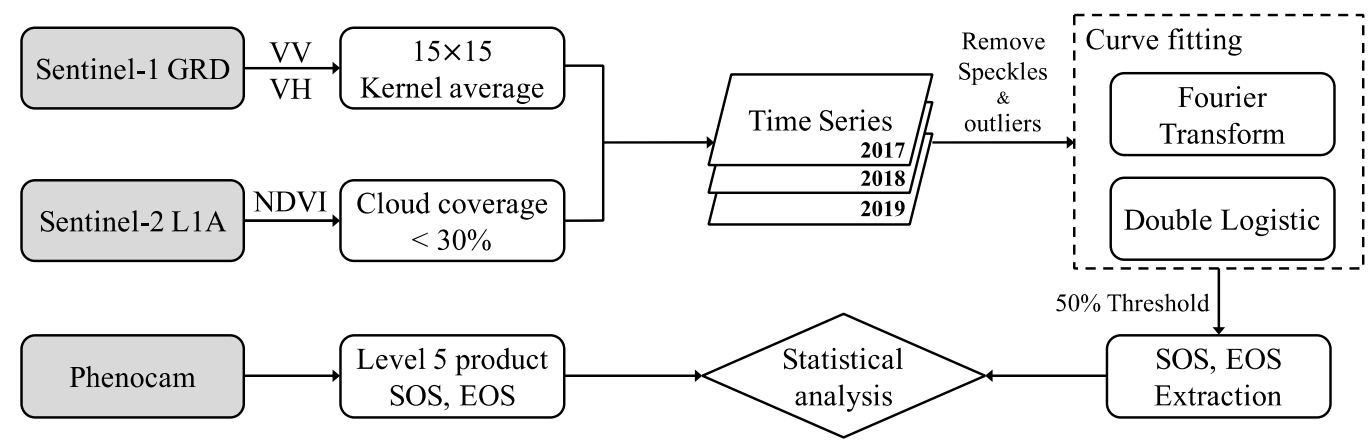

Figure 3. Flowchart for the forest phenology extracting and evaluation.

\section{Results}

Figure 4a,c show the S1 dual-polarization temporal profiles of one representative DB site (D02.SCBI). VV polarization displayed no obvious seasonal variation (annual 
fluctuation is less than $1 \mathrm{~dB})$, while the VH polarization showed a decrease in spring $(-12$ to $-14 \mathrm{~dB}$ ) and an increase in autumn. Moreover, at the $6 \mathrm{EN}$ sites where seasonal variations were observed, the temporal profile of backscatter measurements showed different seasonal trends than that of DB. Figure $4 \mathrm{~b}$ illustrates an example of the backscatter coefficients of the VV and VH in EN, which are similar in seasonal variations, while the amplitude of VH is slightly higher than that of VV (approximately $3 \mathrm{~dB}$ and $1 \mathrm{~dB}$, respectively). The peak value of $\mathrm{VV}-\mathrm{VH}$ in $\mathrm{EN}$, therefore, appeared in the winter, and the valley value was in the summer, opposite to that in DB, as shown in Figure $4 \mathrm{~b}$. Therefore, it would be necessary to analyze the EN phenology with the negative form of band combinations as that for DB.
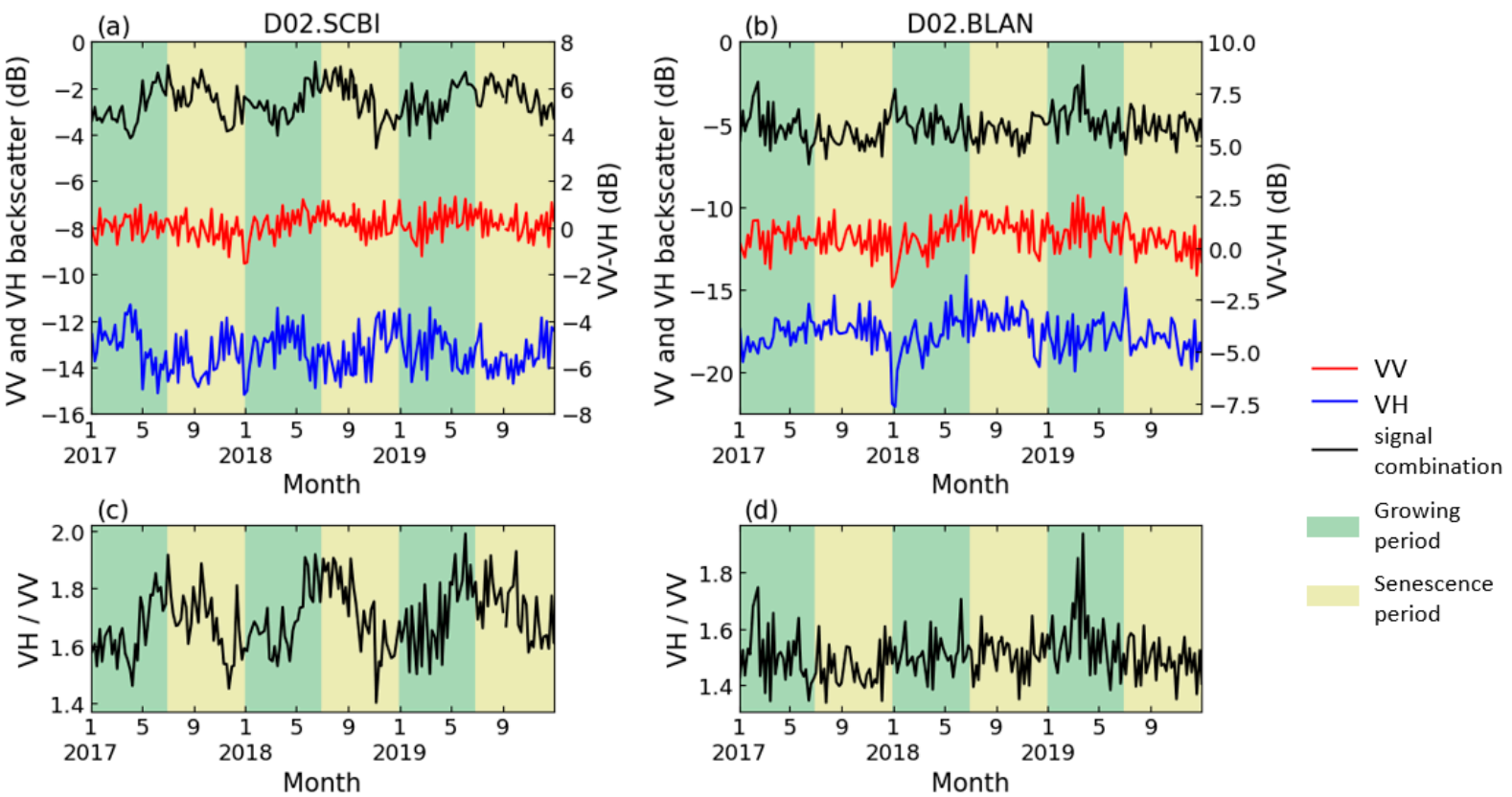

Figure 4. Backscatter coefficient of S1 dual polarization in $(\mathbf{a}, \mathbf{c})$. D02.SCBI (a deciduous site); (b,d). D02.BLAN (a coniferous site).

As discussed above, the S1 C-band backscatter data of the two forest types showed different seasonal patterns. In the following study, we explored the characteristics of different polarization combinations for each forest. Overall, for DB, 12 of the 14 study sites had significant seasonal variation in the time series of $\mathrm{VH} / \mathrm{VV}$, while 9 of them showed significant seasonal variations in VV-VH. At the D01.BART and D11.CLBJ sites, no significant seasonal patterns were detected on the time series of either of the polarization combinations. For evergreen needleleaf forests, only 6 of 12 study sites witnessed seasonal variations in the $\mathrm{VV}-\mathrm{VH}$ time series, and only 3 of them observed seasonal patterns in the VH/VV values. Among coniferous sites, only the D16.WREF and D19.BONA sites showed significant annual changes in the time series of the two combinations at the same time. S1 data exhibited higher accuracy in deciduous forest phenology, but for coniferous forests, seasonal changes were less significant.

Figure 5 displays the VH/VV and VV-VH time series of a typical deciduous forest site smoothed by FT and DL methods, as well as the Gcc time series obtained from the PhenoCam Dataset. The time series of the two tested polarization combinations both showed seasonal variations comparable to Gcc, but VV-VH showed less seasonal variability over the growing season. Both band combinations could extract phenological metrics consistent with the Gcc series. PhenoCam data in coniferous forest sites were partially missing, and at sites with complete observed data, the VH/VV time series could not extract sufficient phenological metrics to support the ability of phenological metric estimation. Figure 6 shows the results of FT applied on VH/VV and VV-VH for one coniferous forest site. It is obvious that the VV-VH graph followed a similar trend as Gcc, although the slope 
of rising and falling is relatively flat; however, the VH/VV combination had no obvious fluctuation in value except for small increases in spring 2017 and summer 2019. Although no literature was found discussing the sufficiency of the differencing combination, some recent papers have all used this combination for phenological research $[21,46]$, which is consistent with the conclusion of this study.

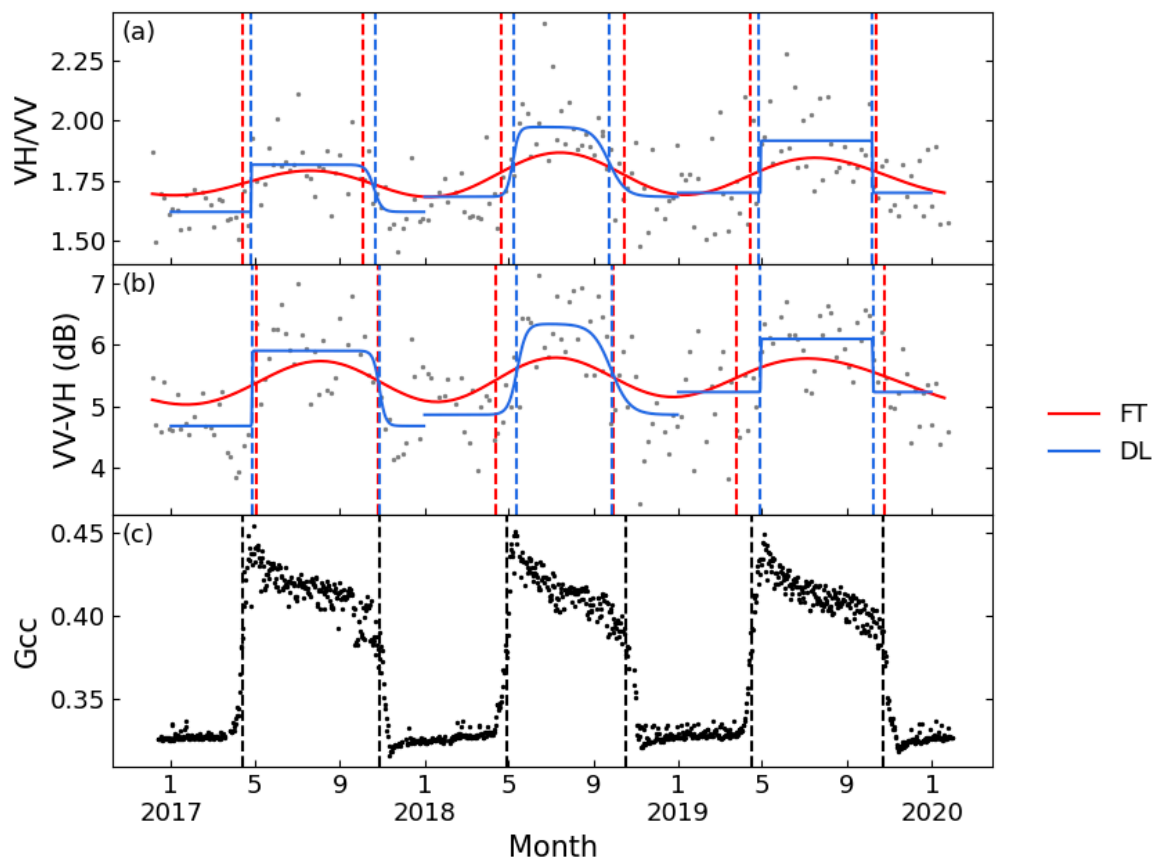

Figure 5. Seasonal patterns of Sentinel-1 for a typical deciduous forest (D02.SCBI) between 2017 and 2019. (a): VH/VV processed by FT and DL; (b): VV-VH processed by FT and DL; and (c): Gcc. Red lines: FT function; blue lines: DL function; and dashed line: phenological metrics.

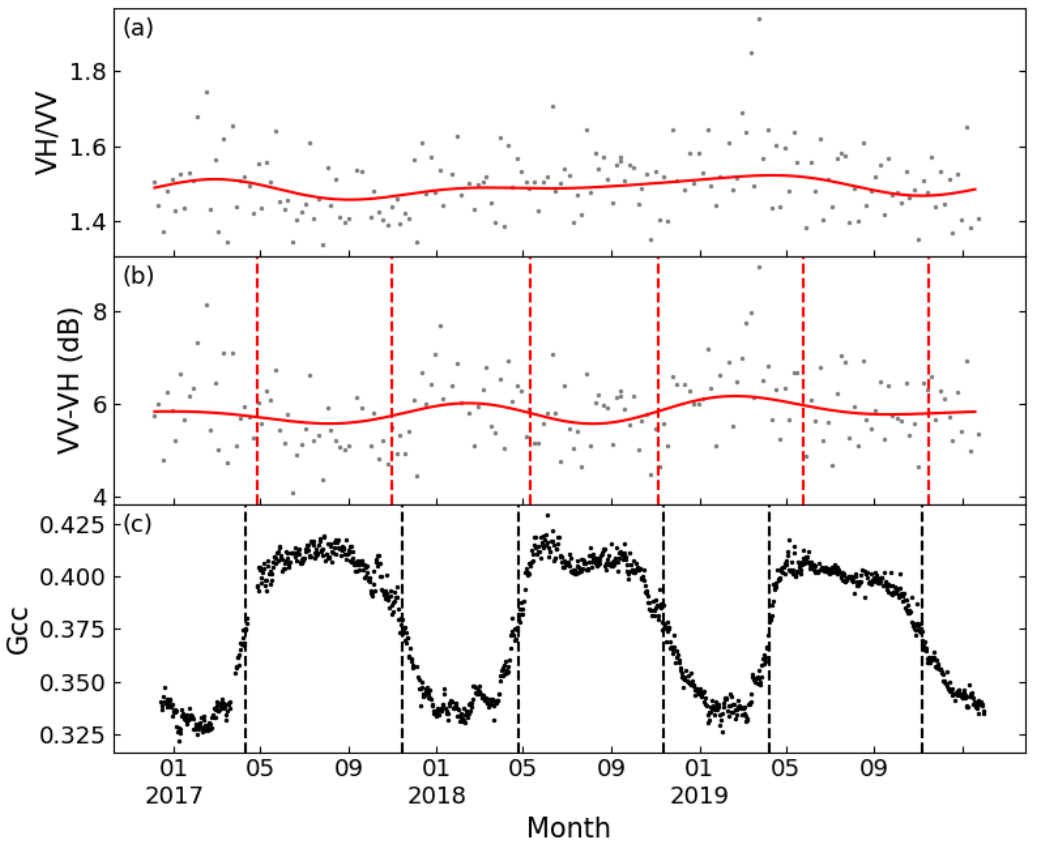

Figure 6. Seasonal patterns of Sentinel-1 for a typical coniferous forest (D02.BLAN) between 2017 and 2019. (a): VH/VV processed by FT (cannot detect any phenological metrics); (b): VV-VH processed by FT; and (c): Gcc. Red lines: FT function; and dashed line: phenological metrics. 
An evaluation of the performance of the satellite-derived phenological metrics was performed by comparison to those obtained from the in-situ PhenoCam dataset (Table 2). In deciduous forest sites, the SOS extracted from VV-VH was strongly correlated with that from Gcc ( $\mathrm{R}^{2}$ values of 0.81 for FT and 0.75 for DL), which exceeded the correlation between the NDVI and Gcc ( $\mathrm{R}^{2}$ values of 0.63 for FT and 0.77 for DL), and the EOS extracted from VV-VH through the DL method was also slightly higher than that from the NDVI.

Table 2. Correlation of Sentinel-1 and Sentinel-2 extracted phenological metrics to PhenoCam extracted metrics (shown by $\mathrm{R}^{2}$ values).

\begin{tabular}{cccccc}
\hline \multirow{2}{*}{ Forest Type } & Index & \multicolumn{2}{c}{ SOS } & \multicolumn{2}{c}{ EOS } \\
\cline { 3 - 6 } & & FT & DL & FT & DL \\
\hline \multirow{2}{*}{ DB } & VH/VV & 0.42 & 0.66 & 0.01 & 0.02 \\
& VV-VH & 0.81 & 0.75 & 0.00 & 0.26 \\
& NDVI & 0.63 & 0.77 & 0.17 & 0.15 \\
\hline \multirow{2}{*}{ EN } & VH/VV & 0.14 & 0.07 & 0.07 & 0.20 \\
& VV-VH & $0.30^{*}$ & 0.20 & 0.20 & 0.01 \\
& NDVI & 0.25 & 0.03 & 0.35 & 0.00 \\
\hline
\end{tabular}

* Negative correlation.

Figures 7 and 8 show the relationships between the in-situ and satellite remote sensing for the extracted phenological metrics. Generally, for deciduous forests, VV-VH had a higher relationship with Gcc, and VH/VV behaved the worst among the calculated indices. For coniferous forest, it is remarkable that the SOS derived from VV-VH using FT had a negative correlation with Gcc phenology, but this negative correlation did not occur when using DL in estimating SOS based on the same data. Additionally, VH/VV cannot effectively extract phenological phases regardless of whether FT or DL was applied as the smoothing algorithm. Due to the lack of PhenoCam data at coniferous forest sites, the correlation between S1 and S2 phenological metrics was also extracted (Table 3). The SOS of DB derived from S1 backscatter is closely related to that of S2 NDVI, with the highest $\mathrm{R}^{2}$ value of 0.72 for VH/VV processed by DL. The EOS of DB and EN both had low correlations with those from the NDVI ( $\mathrm{R}^{2}$ value close to 0$)$, and the SOS extracted from $\mathrm{VV}-\mathrm{VH}$ still had a negative correlation with that from the NDVI.
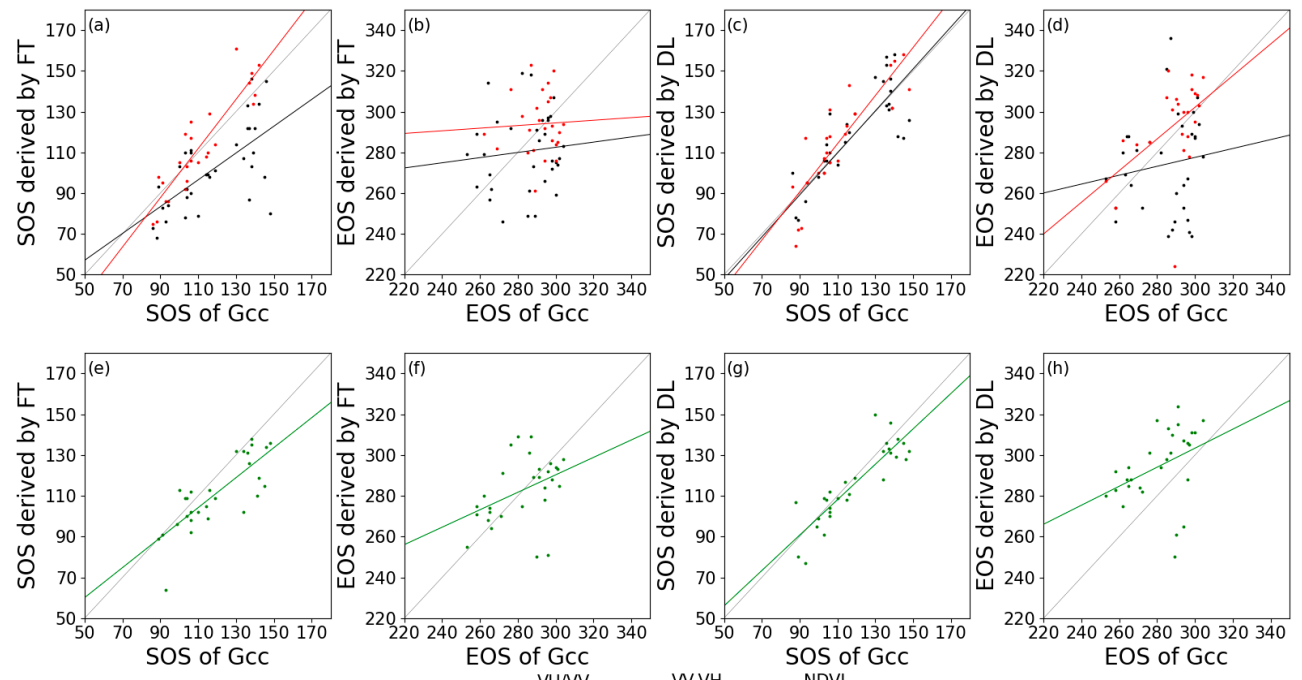

Figure 7. Correlations of phenological metrics in day of year between PhenoCam (x-axis) and satellite remote sensing (y-axis) in deciduous forests. (a,e): SOS extracted by FT; $(\mathbf{b}, \mathbf{f})$ : EOS extracted by FT; $(\mathbf{c}, \mathbf{g})$ : SOS extracted by DL; and (d,h): EOS extracted by DL. Black lines: VH/VV; red lines: VV-VH; and green lines: NDVI. 

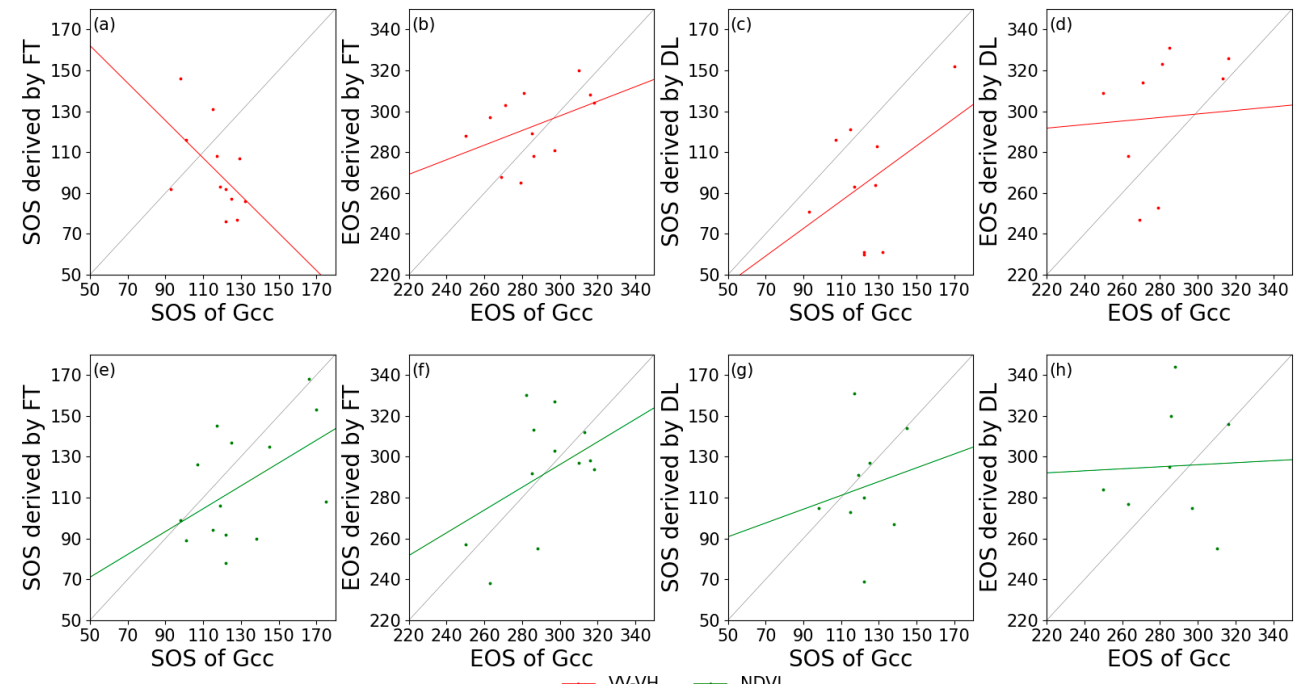

Figure 8. Correlations of phenological metrics in day of year between PhenoCam (x-axis) and satellite remote sensing (y-axis) in coniferous forests. $(\mathbf{a}, \mathbf{e})$ : SOS extracted by FT; $(\mathbf{b}, \mathbf{f})$ : EOS extracted by FT; $(\mathbf{c}, \mathbf{g})$ : SOS extracted by DL; and (d,h): EOS extracted by DL. Red lines: VV-VH; and green lines: NDVI.

Table 3. Correlation between Sentinel-1 and Sentinel-2 NDVI extracted phenological metrics (shown by $\mathrm{R}^{2}$ values).

\begin{tabular}{cccccc}
\hline \multirow{2}{*}{ Forest Type } & \multirow{2}{*}{ Index } & \multicolumn{2}{c}{ SOS } & \multicolumn{2}{c}{ EOS } \\
\cline { 3 - 6 } & & FT & DL & FT & DL \\
\hline \multirow{2}{*}{ DB } & VH/VV & 0.30 & 0.72 & 0.01 & 0.00 \\
& VV-VH & 0.61 & 0.50 & 0.00 & 0.10 \\
\hline \multirow{2}{*}{ EN } & VV-VH & $0.10^{*}$ & 0.35 & 0.01 & 0.01 \\
\hline
\end{tabular}

${ }^{*}$ Negative correlation.

\section{Discussion}

Our results confirmed the potential of S1 for monitoring deciduous forest phenology [1], and, more importantly, we also discovered quite different performances for the coniferous forest phenology. These were possibly caused by the difference in SAR polarization backscattering behavior between different forests. For deciduous forests, the absorption and forward scattering of radar signals by foliage are more than that of backscattering [47]; therefore, the backscattering decreases significantly during the leaf-on period, which is consistent with the discovery of this research. Furthermore, it has also been discussed that the co-polarization of the C-band (VV of S1) is related to the vertical structure of forests [17-19], while cross-polarization (VH of S1) is related to forest canopy volume. It can therefore be explained that no signal variations occurred in the vertical structure, while the VH backscattering decreased rapidly because of the foliage dynamics. This difference causes seasonal variation in the ratio and differencing combinations and indicates the strong potential of S1 data to estimate the phenology of deciduous broadleaf forest. The amplitude of $\mathrm{VH}$ was higher than VV in 6 out of 12 coniferous sites in this study, but Dostálová et al. [48] and Frison et al. [1] pointed out that the amplitude of VV was higher than that of $\mathrm{VH}$ in their research (2.40 dB for $\mathrm{VV}$ and $2.08 \mathrm{~dB}$ for $\mathrm{VH}$ [48]). One possible explanation for this inconsistency could be the difference in the types of coniferous forests studied. Based on visual inspection of images in PhenoCam Level 2 products, the coniferous forests studied in this research are possible types with short needles, such as spruces and short-leaf pines, while the VH backscatter of coniferous forests was negatively correlated with the length of needle leaves [47], and this can be the reason for the amplitude of $\mathrm{VH}$ backscatter exceeding that of VV. Because of the negative correlation between the $\mathrm{VH}$ polarization and needle length, the polarization combinations may show different seasonal 
patterns among the forest types and may not show obvious seasonal variation when the amplitude of $\mathrm{VH}$ is close to that of $\mathrm{VV}$, and this may be the reason for the 6 sites that did not show significant variations in $\mathrm{VV}-\mathrm{VH}$. Therefore, further research is required on the potential of S1 data for monitoring coniferous forest phenology.

Previous studies have shown the stability of the NDVI for phenological studies [49]. A recent study also indicated that the phenological estimation results for comprehensive vegetation types based on S1 C-band backscatter are less accurate than those of S2 NDVI [20]. This study partly concurs with their conclusion about coniferous forest phenological estimation. The unexplained negative SOS correlation between S1 and PhenoCam and the instability of the VV-VH profile indicates that the tested algorithm in this research may not be suitable for the extraction of coniferous forest phenology. Therefore, S2 data are more suitable for large-scale phenological observations of coniferous forests. For deciduous forest sites, S1 data showed a higher accuracy of phenological estimation than S2 data. Although seasonal variations could not be extracted stably from all study sites based on S1 signal profiles, they still showed better continuity in time series than S2 NDVI results because optical remote sensing satellites can be affected by cloud coverage and cause the loss of data for a continuous period. Generally, although S2 performs better than S1 on coniferous forest phenological estimation, the continuity of S1 data was clearly better than S2 and will have better research potential.

In this research, the SOS extracted from satellite data had a satisfying correlation with the rising transition date of Gcc, but the correlation of EOS was relatively poor. We suggest that this may be caused by the difference in seasonal variation drivers between SAR backscattering, NDVI, and Gcc, which may have nonlinear relationships. To be clear, C-band backscatters are affected by canopy structures [17-19], NDVI is affected by leaf microstructures, while Gcc is influenced by leaf greenness, leaf area index, and pigmentation [49]. Previous work also discovered the inconsistency between Gcc time series and VI time series at the end of the growing season and listed some possible explanations $[32,49,50]$. This could be the main reason for the low accuracy of EOS estimation in this research but cannot completely explain why the EOS correlation was significantly lower than that in other studies. The noise in the S1 time series and the difference in the smoothing algorithm used (this research applied FT and DL, while PhenoCam applied spline interpolation) could also play a minor role. Although the same smoothing algorithm and phenological extraction algorithm were applied, the coherence between the S1 polarization combination and S2 NDVI was not satisfactory for EOS and evergreen needleleaf forests (Table 3), which might also be because of the difference in the driving factors of seasonal variation. However, limited by research conditions, no further investigation or development was carried out on this aspect.

Affected by environmental variables such as weather and temperature, this research did not obtain sufficient remote sensing data of coniferous forest, while the phenological measurements in PhenoCam products were also missing. Therefore, the statistical analysis for the accuracy of coniferous forest phenology estimation is not reliable to some degree. In future research, more near-surface remote sensing data can be introduced for quantitative analysis, and in-situ data can be collected to enrich the phenological measurements when necessary. Further smoothing methods such as the Savitzky-Golay filter would be considered in future studies to improve the curve fitting results.

\section{Conclusions}

By exploring remote sensing data from 14 deciduous broadleaf forest sites and 12 evergreen needleleaf forest sites, this research analyzed the difference in seasonal variations in the S1 backscatter coefficient between deciduous forest and coniferous forest and assessed their accuracy to estimate forest phenology. The co-polarization of the two forests is both positively correlated with the forest vertical structure and follows similar variations, while the cross-polarization differs. During the leaf-on period, the foliage of deciduous forests can absorb and front scatter the cross-polarization signals, which causes a decrease in 
backscattering. Coniferous forests do not show significant foliage dynamics, but the annual amplitude of the cross-polarization is possibly negatively correlated with the length of needle leaves, which may cause instability in seasonal variation of VV-VH signals. We also discovered that both $\mathrm{VH} / \mathrm{VV}$ and VV-VH can be exploited to monitor deciduous forest phenology, and VV-VH is more stable in annual amplitudes and performs better at coniferous forest sites. Although the time series can satisfactorily characterize seasonal variations, the satellite data performed poorly in extracting EOS compared with Gcc measurements. Further research can focus on exploring the non-linear relationships of phenological retrieval between different data sources. Overall, S1 backscatter measurements can better characterize the SOS of DB but are not satisfactory for EOS of DB and EN phenology.

Author Contributions: Conceptualization, Y.L., S.T. and C.L.; data curation, Y.L.; methodology, Y.L., C.L. and J.D.; validation, Y.L., S.T., C.L., J.D., H.M. and J.P.-G.; writing-original draft preparation, Y.L.; writing-review and editing, S.T., C.L., J.D., H.M. and J.P.-G. All authors have read and agreed to the published version of the manuscript.

Funding: This research was supported by National Key Research and Development Program of China (2018YFC1506502).

Institutional Review Board Statement: Not applicable.

Informed Consent Statement: Not applicable.

Data Availability Statement: Restrictions apply to the availability of these data. PhenoCam data was obtained from [NEON] and are available [https: / www.neonscience.org/field-sites/explorefield-sites] (accessed on 25 June 2020) with the permission of [NEON]. Sentinel-1 and -2 data was obtained from [European Space Agency] and are available [https:/ / sentinel.esa.int/web/sentinel/ sentinel-data-access/sentinel-products] (accessed on 25 June 2020) with the permission of [European Space Agency].

Conflicts of Interest: The authors declare no conflict of interest.

\section{References}

1. Frison, P.-L.; Fruneau, B.; Kmiha, S.; Soudani, K.; Dufrêne, E.; Le Toan, T.; Koleck, T.; Villard, L.; Mougin, E.; Rudant, J.-P. Potential of Sentinel-1 Data for Monitoring Temperate Mixed Forest Phenology. Remote Sens. 2018, 10, 2049. [CrossRef]

2. Rüetschi, M.; Schaepman, M.E.; Small, D. Using multitemporal Sentinel-1 C-band backscatter to monitor phenology and classify deciduous and coniferous forests in Northern Switzerland. Remote Sens. 2018, 10, 55. [CrossRef]

3. Gill, A.L.; Gallinat, A.S.; Sanders-DeMott, R.; Rigden, A.J.; Short Gianotti, D.J.; Mantooth, J.A.; Templer, P.H. Changes in autumn senescence in northern hemisphere deciduous trees: A meta-analysis of autumn phenology studies. Ann. Bot. 2015, 116, 875-888. [CrossRef] [PubMed]

4. Piao, S.; Tan, J.; Chen, A.; Fu, Y.H.; Ciais, P.; Liu, Q.; Janssens, I.A.; Vicca, S.; Zeng, Z.; Jeong, S.-J.; et al. Leaf onset in the northern hemisphere triggered by daytime temperature. Nat. Commun. 2015, 6, 6911. [CrossRef] [PubMed]

5. $\quad$ Elmendorf, S.C.; Jones, K.D.; Cook, B.I.; Diez, J.M.; Enquist, C.A.F.; Hufft, R.A.; Jones, M.O.; Mazer, S.J.; Miller-Rushing, A.J.; Moore, D.J.P.; et al. The plant phenology monitoring design for The National Ecological Observatory Network. Ecosphere 2016, 7, e01303. [CrossRef]

6. Dragoni, D.; Rahman, A.F. Trends in fall phenology across the deciduous forests of the Eastern USA. Agric. For. Meteorol. 2012, 157, 96-105. [CrossRef]

7. Morin, X.; Lechowicz, M.J.; Augspurger, C.; O'keefe, J.; Viner, D.; Chuine, I. Leaf phenology in 22 North American tree species during the 21st century. Glob. Chang. Biol. 2009, 15, 961-975. [CrossRef]

8. Zeng, L.; Wardlow, B.D.; Xiang, D.; Hu, S.; Li, D. A review of vegetation phenological metrics extraction using time-series, multispectral satellite data. Remote Sens. Environ. 2020, 237, 111511. [CrossRef]

9. Menzel, A.; Dose, V. Analysis of long-term time series of the beginning of flowering by Bayesian function estimation. Meteorol. Z. 2005, 14, 429-434. [CrossRef]

10. Mayer, A. Phenology and Citizen Science. Bioscience 2010, 60, 172-175. [CrossRef]

11. Liang, L.; Schwartz, M.D.; Wang, Z.; Gao, F.; Schaaf, C.B.; Tan, B.; Morisette, J.T.; Zhang, X. A Cross comparison of spatiotemporally enhanced springtime phenological measurements from satellites and ground in a northern U.S. mixed forest. IEEE Trans. Geosci. Remote Sens. 2014, 52, 7513-7526. [CrossRef]

12. Watson, C.J.; Restrepo-coupe, N.; Huete, A.R.; Hill, M.J. Multi-Scale Phenology of Temperate Grasslands: Improving Monitoring and Management With Near-Surface Phenocams. Front. Environ. Sci. 2019, 7, 14. [CrossRef] 
13. Moulin, S.; Kergoat, L.; Viovy, N.; Dedieu, G. Global-Scale Assessment of Vegetation Phenology Using NOAA/AVHRR Satellite Measurements. J. Clim. 1997, 10, 1154-1170. [CrossRef]

14. Liu, Y.; Hill, M.J.; Zhang, X.; Wang, Z.; Richardson, A.D.; Hufkens, K.; Filippa, G.; Baldocchi, D.D.; Ma, S.; Verfaillie, J.; et al Using data from Landsat, MODIS, VIIRS and PhenoCams to monitor the phenology of California oak/grass savanna and open grassland across spatial scales. Agric. For. Meteorol. 2017, 237-238, 311-325. [CrossRef]

15. Torres, R.; Snoeij, P.; Geudtner, D.; Bibby, D.; Davidson, M.; Attema, E.; Potin, P.; Rommen, B.; Floury, N.; Brown, M.; et al. GMES Sentinel-1 mission. Remote Sens. Environ. 2012, 120, 9-24. [CrossRef]

16. Frampton, W.J.; Dash, J.; Watmough, G.; Milton, E.J. Evaluating the capabilities of Sentinel-2 for quantitative estimation of biophysical variables in vegetation. ISPRS J. Photogramm. Remote Sens. 2013, 82, 83-92. [CrossRef]

17. Xin, J.; Yu, Z.; van Leeuwen, L.; Driessen, P.M. Mapping crop key phenological stages in the North China Plain using NOAA time series images. Int. J. Appl. Earth Obs. Geoinf. 2002, 4, 109-117. [CrossRef]

18. Nasrallah, A.; Baghdadi, N.; Hajj, M.E.; Darwish, T.; Belhouchette, H.; Faour, G.; Darwich, S.; Mhawej, M. Sentinel-1 Data for Winter Wheat Phenology Monitoring and Mapping. Remote Sens. 2019, 11, 2228. [CrossRef]

19. Mercier, A.; Betbeder, J.; Baudry, J.; Le Roux, V.; Spicher, F.; Lacoux, J.; Roger, D.; Hubert-Moy, L. Evaluation of Sentinel-1 \& 2 time series for predicting wheat and rapeseed phenological stages. ISPRS J. Photogramm. Remote Sens. 2020, 163, 231-256. [CrossRef]

20. Stendardi, L.; Karlsen, S.R.; Niedrist, G.; Gerdol, R.; Zebisch, M.; Rossi, M.; Notarnicola, C. Exploiting time series of Sentinel-1 and Sentinel-2 imagery to detect meadow phenology in mountain regions. Remote Sens. 2019, 11, 542. [CrossRef]

21. Laurin, G.V.; Balling, J.; Corona, P.; Mattioli, W.; Papale, D.; Puletti, N.; Rizzo, M.; Truckenbrodt, J.; Urban, M. Above-ground biomass prediction by Sentinel-1 multitemporal data in central Italy with integration of ALOS2 and Sentinel-2 data. J. Appl. Remote Sens. 2018, 12, 1. [CrossRef]

22. Khudinyan, M.; Silva, J.; Guerrero, I. The Use of Remotely Sensed Data for Forest Biomass Monitoring: A Case of Forest Sites in North-Eastern Armenia. Ph.D. Thesis, Universidade Nova de Lisboa, Lisbon, Portugal, 2019.

23. Xue, J.; Yu, L.; Lin, Q.; Liu, G.; Huang, H. Using Sentinel-1 multitemporal InSAR data to monitor the damage degree of shoot beetle in Yunnan pine forest. Remote Sens. L. Resour. 2018, 30, 108-114. [CrossRef]

24. Keller, M.; Schimel, D.S.; Hargrove, W.W.; Hoffman, F.M. A continental strategy for the National Ecological Observatory Network. Front. Ecol. Environ. 2008, 6, 282-284. [CrossRef]

25. National Ecological Observatory Network (NEON) Field Sites. Available online: https://www.neonscience.org/field-sites/fieldsites-map/list (accessed on 25 June 2020).

26. Seyednasrollah, B.; Richardson, A.D.; Hufkens, K.; Milliman, T.; Aubrecht, D.M.; Chen, M.; Gray, J.M.; Johnston, M.R.; Keenan, T.F.; Klosterman, S.T.; et al. PhenoCam Dataset v2.0: Vegetation Phenology from Digital Camera Imagery, 2000-2018. Available online: https: / / daac.ornl.gov/cgi-bin/dsviewer.pl?ds_id=1674 (accessed on 25 June 2020).

27. Sonnentag, O.; Hufkens, K.; Teshera-sterne, C.; Young, A.M.; Friedl, M.; Braswell, B.H.; Milliman, T.; Keefe, J.O.; Richardson, A.D Meteorology digital repeat photography for phenological research in forest ecosystems. Agric. For. Meteorol. 2012, 152, $159-177$. [CrossRef]

28. Moore, C.E.; Brown, T.; Keenan, T.F.; Duursma, R.A.; Van Dijk, A.I.J.M.; Beringer, J.; Culvenor, D.; Evans, B.; Huete, A.; Hutley, L.B.; et al. Reviews and syntheses: Australian vegetation phenology: New insights from satellite remote sensing and digital repeat photography. Biogeosciences 2016, 13, 5085-5102. [CrossRef]

29. Tang, J.; Körner, C.; Muraoka, H.; Piao, S.; Shen, M.; Thackeray, S.J.; Yang, X. Emerging opportunities and challenges in phenology: A review. Ecosphere 2016, 7, e1436. [CrossRef]

30. Seyednasrollah, B.; Young, A.M.; Hufkens, K.; Milliman, T.; Friedl, M.A.; Frolking, S.; Richardson, A.D. Tracking vegetation phenology across diverse biomes using Version 2.0 of the PhenoCam Dataset. Sci. Data 2019, 6, 222. [CrossRef]

31. Vrieling, A.; Meroni, M.; Darvishzadeh, R.; Skidmore, A.K.; Wang, T.; Zurita-Milla, R.; Oosterbeek, K.; O'Connor, B.; Paganini, M. Vegetation phenology from Sentinel-2 and field cameras for a Dutch barrier island. Remote Sens. Environ. 2018, 215, 517-529. [CrossRef]

32. Brown, L.A.; Dash, J.; Ogutu, B.O.; Richardson, A.D. On the relationship between continuous measures of canopy greenness derived using near-surface remote sensing and satellite-derived vegetation products. Agric. For. Meteorol. 2017, 247, $280-292$. [CrossRef]

33. Richardson, A.D.; Hufkens, K.; Milliman, T.; Aubrecht, D.M.; Chen, M.; Gray, J.M.; Johnston, M.R.; Keenan, T.F.; Klosterman, S.T.; Kosmala, M.; et al. Tracking vegetation phenology across diverse North American biomes using PhenoCam imagery. Sci. Data 2018, 5, 180028. [CrossRef]

34. European Space Agency (ESA) Sentinel-1—Overview. Available online: https://sentinel.esa.int/web/sentinel/missions/sentinel1/overview (accessed on 2 September 2020).

35. Drusch, M.; Del Bello, U.; Carlier, S.; Colin, O.; Fernandez, V.; Gascon, F.; Hoersch, B.; Isola, C.; Laberinti, P.; Martimort, P.; et al. Sentinel-2: ESA's Optical High-Resolution Mission for GMES Operational Services. Remote Sens. Environ. 2012, 120, 25-36. [CrossRef]

36. Rouse, J.W.; Haas, R.H.; Schell, J.A.; Deering, D.W. Monitoring vegetation systems in the Great Plains with ERTS. In Proceedings of the 3rd ERTS Symposium, NASA SP-351, Washington, DC, USA, 10-14 December 1973; pp. 309-317.

37. Eklundh, L.; Jönsson, P. TIMESAT 3.3 with Seasonal Trend Decomposition and Parallel Processing Software Manual; Lund University: Lund, Sweden, 2017; pp. 1-92. 
38. Moody, A.; Johnson, D.M. Land-surface phenologies from AVHRR using the discrete fourier transform. Remote Sens. Environ. 2001, 75, 305-323. [CrossRef]

39. Sellers, P.J.; Tucker, C.J.; Collatz, G.J.; Los, S.O.; Justice, C.O.; DAZLICH, D.A.; Randall, D.A. A global $1^{\circ}$ by $1^{\circ}$ NDVI data set for climate studies. Part 2: The generation of global fields of terrestrial biophysical parameters from the NDVI. Int. J. Remote Sens. 1994, 15, 3519-3545. [CrossRef]

40. Wagenseil, H.; Samimi, C. Assessing spatio-temporal variations in plant phenology using Fourier analysis on NDVI time series: Results from a dry savannah environment in Namibia. Int. J. Remote Sens. 2006, 27, 3455-3471. [CrossRef]

41. Atkinson, P.M.; Jeganathan, C.; Dash, J.; Atzberger, C. Inter-comparison of four models for smoothing satellite sensor time-series data to estimate vegetation phenology. Remote Sens. Environ. 2012, 123, 400-417. [CrossRef]

42. Pastor-Guzman, J.; Dash, J.; Atkinson, P.M. Remote sensing of mangrove forest phenology and its environmental drivers. Remote Sens. Environ. 2018, 205, 71-84. [CrossRef]

43. Beck, P.S.A.; Atzberger, C.; Høgda, K.A.; Johansen, B.; Skidmore, A.K. Improved monitoring of vegetation dynamics at very high latitudes: A new method using MODIS NDVI. Remote Sens. Environ. 2006, 100, 321-334. [CrossRef]

44. Harris, C.R.; Millman, K.J.; van der Walt, S.J.; Gommers, R.; Virtanen, P.; Cournapeau, D.; Wieser, E.; Taylor, J.; Berg, S.; Smith, N.J.; et al. Array programming with NumPy. Nature 2020, 585, 357-362. [CrossRef]

45. Virtanen, P.; Gommers, R.; Oliphant, T.E.; Haberland, M.; Reddy, T.; Cournapeau, D.; Burovski, E.; Peterson, P.; Weckesser, W.; Bright, J.; et al. SciPy 1.0: Fundamental algorithms for scientific computing in Python. Nat. Methods 2020, 17, 261-272. [CrossRef]

46. Soudani, K.; Delpierre, N.; Berveiller, D.; Hmimina, G.; Vincent, G.; Morfin, A.; Dufrêne, É. Potential of C-band Synthetic Aperture Radar Sentinel-1 time-series for the monitoring of phenological cycles in a deciduous forest. Int. J. Appl. Earth Obs. Geoinf. 2021, 104, 102505. [CrossRef]

47. Ahern, F.J.; Leckie, D.J.; Drieman, J.A. Seasonal changes in relative C-band backscatter of northern forest cover types. IEEE Trans. Geosci. Remote Sens. 1993, 31, 668-680. [CrossRef]

48. Dostálová, A.; Milenković, M.; Hollaus, M.; Wagner, W. Influence of forest structure on the Sentinel-1 backscatter variation-analysis with full-waveform lidar data. Living Planet Symp. 2016, SP-740.

49. Keenan, T.F.; Darby, B.; Felts, E.; Sonnentag, O.; Friedl, M.A.; Hufkens, K.; O’Keefe, J.; Klosterman, S.; Munger, J.W.; Toomey, M.; et al. Tracking forest phenology and seasonal physiology using digital repeat photography: A critical assessment. Ecol. Appl. 2014, 24, 1478-1489. [CrossRef] [PubMed]

50. Richardson, A.D.; Keenan, T.F.; Migliavacca, M.; Ryu, Y.; Sonnentag, O.; Toomey, M. Climate change, phenology, and phenological control of vegetation feedbacks to the climate system. Agric. For. Meteorol. 2013, 169, 156-173. [CrossRef] 